\title{
BMJ Open Knowledge of neonatal danger signs and associated factors among husbands of mothers who gave birth in the last 6 months in Gurage Zone, Southern Ethiopia, 2020: a community-based cross-sectional study
}

\author{
Solomon Shitu (D) , ${ }^{1}$ Haimanot Abebe (D) , ${ }^{1}$ Daniel Adane (D) , ${ }^{1}$ Abebaw Wassie, \\ Ayenew Mose (D) , ${ }^{1}$ Alex Yeshaneh (D) ${ }^{2}$
}

To cite: Shitu S, Abebe $\mathrm{H}$ Adane D, et al. Knowledge of neonatal danger signs and associated factors among husbands of mothers who gave birth in the last 6 months in Gurage Zone, Southern Ethiopia, 2020: a community-based cross-sectional study. BMJ Open 2021;11:e045930. doi:10.1136/ bmjopen-2020-045930

- Prepublication history for this paper is available online To view these files, please visit the journal online (http://dx.doi org/10.1136/bmjopen-2020045930).

Received 19 0ctober 2020 Accepted 27 July 2021

Check for updates

(c) Author(s) (or their employer(s)) 2021. Re-use permitted under CC BY-NC. No commercial re-use. See rights and permissions. Published by BMJ.

${ }^{1}$ Department of Midwifery, Wolkite University, Welkite, Ethiopia

${ }^{2}$ Midwifery, Wolkite University, Wolkite, Ethiopia

Correspondence to

Mr Solomon Shitu;

solomonsht7@gmail.com

\section{ABSTRACT}

Objective To assess knowledge of neonatal danger signs and their associations among husbands of mothers who gave birth in the last 6 months in Gurage Zone, Southern Ethiopia, from 1 February to 28 February 2020.

Design Community-based cross-sectional study.

Setting Gurage Zone, Southern Ethiopia.

Participants The study was conducted among 633 participants living in Gurage Zone from 1 February to 28 February 2020.618 completed the questionnaire. A multistage sampling technique was employed to obtain study participants. Data were collected through face-toface interviews conducted by 20 experienced and trained data collectors using a pretested structured questionnaire. To assess knowledge, 10 questions were adopted from the WHO questionnaire, which is a standardised and structured questionnaire used internationally. Data were entered into EpiData V.3.1 and exported to SPSS (Statistical Package for Social Sciences) V.24 for analysis. Descriptive statistics were performed and the findings were presented in text, figures and tables. Binary logistic regression was used to assess the association between each independent variable and the outcome variable. All variables with $p<0.25$ in the bivariate analysis were included in the final model and statistical significance was declared at $p<0.05$. Voluntary consent was taken from all participants.

Results A total of 618 participants were included in the study, with a response rate of $97.6 \%$. Of the participants, $40.7 \%$ had good knowledge $(95 \% \mathrm{Cl} 36.3$ to 44.2$)$. Urban residence (adjusted OR=6.135, 95\% Cl 4.429 to 9.238) and a primary and above educational level (adjusted OR=4.294, 95\% Cl 1.875 to 9.831) were some independent predictors of husbands' knowledge status. Conclusion Knowledge of neonatal danger signs in this study was low. Urban residence, primary and above educational level, the husband's wife undergoing instrumental delivery and accompanying the wife during antenatal care visits were independent predictors of knowledge. Thus, strong multisectoral collaboration should target reducing the knowledge gap by improving husbands' attitude with regard to accompanying their
Strengths and limitations of this study

To the best of our knowledge, this is the first study to be carried out in the study area and in the southern region of Ethiopia.

- The study employed a nationally validated assessment tool.

- This was a community-based survey designed to explore factors that can predict knowledge status by focusing on those who cannot visit health institutions due to different factors.

- Predictors of knowledge of danger signs would have been best addressed if the study included both the husband and the wife as study participants for comparison.

wives during antenatal care and postnatal care visits, or create a strategy to increase husbands' participation in access to maternal and child health service since husbands are considered decision-makers when it comes to healthcare-seeking in the family. The government should come up with policies that will help promote formal education in the community and increase their media access.

\section{BACKGROUND}

The neonatal period refers to the period from birth to 28 days and is the most critical period of the baby's life as many complications and death may occur. The major contributor to newborn morbidity and mortality is delay in recognising newborn danger signs. Common danger signs include poor or no sucking, lethargy or drowsiness, difficulty in breathing, hypothermia, hyperthermia, yellowish discolouration of the palms and soles, bleeding from the umbilical cord, diarrhoea, convulsion and vomiting. ${ }^{1-5}$ 
Globally, neonatal mortality, accounting for an estimated four million deaths worldwide each year, constitutes $40 \%$ of under- 5 mortality and approximately $57 \%$ of infant mortality. Most neonatal deaths (99\%) come from low-income and middle-income countries and approximately half occur at home. Across countries, neonatal mortality rates (NMRs) ranged from 46 deaths per 1000 live births in Pakistan to 1 per 1000 live births in Iceland and Japan. $^{6-8}$

Childhood mortality is decreasing in Ethiopia. Approximately $42 \%$ of under-5 mortality in Ethiopia are attributable to neonatal deaths. According to the Ethiopian Demographic and Health Survey in 2016, NMR in Ethiopia and in the Southern Nations, Nationalities, and Peoples' Region (SNNPR) has remained stable at 30 and 35 deaths per 1000 live births, respectively. According to a study done in the country in 2013 by Mekonnen and his colleagues, ${ }^{9}$ NMR, early NMR and late NMR were 36.7, 29.2 and 7.5 per 1000 population, respectively. Most neonatal deaths happen at home, indicating that lack of early recognition of the danger signs, decision-making and low treatment-seeking practices among mothers (caretakers) are significant contributors. ${ }^{6-12}$

Sustainable Development Goal 3 aimed to reduce neonatal mortality to at least as low as 12 per 1000 live births. Early identification with prompt and appropriate healthcare-seeking of the family serves as the backbone for reducing neonatal mortality. Trends in Ethiopian society so far recognised mothers as caretakers of the majority of neonates while husbands are responsible for decisionmaking when it comes to healthcare-seeking. ${ }^{13-15}$

Some studies in Ethiopia have assessed mothers' knowledge of neonatal danger signs and have identified some factors that affect knowledge; however, knowledge concerning the role of men in neonatal care in Africa is understudied despite their economic dominance and decision-making power. In a patriarchal society like Ethiopia, pregnancy and childbirth are often regarded as exclusively women's affairs. Men are socially and economically dominant; they exert strong influence over their wives in terms of access to healthcare. This makes men critical partners in the improvement of child healthcare and in the reduction of neonatal mortality. ${ }^{10}$ To increase awareness about neonatal danger signs and to reduce mortality and morbidity, knowing the current status of knowledge among husbands is necessary. This study aimed to assess husbands' knowledge of neonatal danger signs and their predictors.

\section{METHODS}

\section{Study area, design and period}

A community-based cross-sectional study was conducted in Gurage Zone from 1 February to 28 February 2020. The study was conducted in the selected woreda of Gurage Zone in Southern Ethiopia. According to the data obtained from the zonal administration, Gurage Zone is one of the administrative zones in SNNPR in Ethiopia.
It has 16 districts and 5 town administrations. The town of Wolkite is the zone's capital. According to the 2017 Ethiopian Central Statistical Agency population projection, Gurage Zone has a total population of 1635 311, of these 842065 were female and the remaining 793246 were male. ${ }^{16}$ There are seven hospitals (five public and two non-government) serving the zone's total population. Five of the hospitals in the zone are primary hospitals, and the remaining two are general zonal hospitals. All hospitals found in Gurage Zone provide comprehensive emergency obstetric care services for saving the lives of women and their children. Additionally, 72 health centres provide basic emergency obstetric care services.

\section{Source population}

The study population was sourced from husbands in Gurage Zone with children less than 6 months of age.

\section{Study population}

The study population included husbands with children less than 6 months of age in randomly selected kebeles of Gurage Zone.

\section{Inclusion criteria}

All husbands with children less than 6 months of age and who were residents of Gurage Zone for at least 6 months were included in the study.

\section{Exclusion criteria}

Husbands who were seriously ill and unable to respond at the time of data collection were excluded.

\section{Sample size determination}

Separate sample size was calculated for each specific objective (to determine the magnitude of husbands' knowledge of neonatal danger signs and to identify the factors associated with knowledge of neonatal danger signs) by using both single and double population proportion formula. The sample size for the first objective (to determine the magnitude of husbands' knowledge of neonatal danger signs) was calculated using the single population proportion formula,

$$
n=\frac{(Z \alpha / 2)^{2} P(1-P)}{d^{2}}
$$

with the following assumptions: $\mathrm{n}=$ minimum sample size required for the study, $(\mathrm{Z} \alpha / 2)^{2}=$ standard normal distribution with $95 \% \mathrm{CI}, \mathrm{P}=50 \%$ men's knowledge of danger signs (due to the absence of previous findings on men in Ethiopia), and $\mathrm{d}=\mathrm{a}$ tolerable margin of error $(\mathrm{d}=0.04)$. The sample size for the second objective was calculated by Epi Info V.7 Stat Cal using different factors. The sample size for the first objective was greater than that of the second objective. The final sample size was derived by adding a non-response rate of $10 \%$. A design effect of 1.5 was used because the sampling procedure was a population-based, one-stage cluster sampling. The calculated sample size for this study was 633 . 


\section{Sampling procedure}

A multistage cluster sampling method was used to draw the final sample size. Gurage Zone has 16 districts and 5 town administrations. From these districts and town administrations, we selected five districts and two town administrations by simple random sampling technique using lottery method. For the districts, Cheha, Muhur Aklil, Mesqan, Mareqo and Abeshge were selected, and for town administrations Emdebir and Butajira Town were selected. Three kebeles from each selected district were chosen randomly. Households with husbands with children less than 6 months of age within the selected kebeles were listed from the family folder of the health extension workers. The total sample size was allocated proportionally to the selected kebeles and towns based on the number of husbands in their respective kebeles and all husbands who participated.

\section{Patient and public involvement}

No patients were involved.

\section{Dependent variable}

The dependent variable is husbands' knowledge of neonatal danger signs. To assess husbands' level of knowledge of neonatal danger signs, a total of 10 yes/no answer questions were asked: is difficulty/fast breathing a danger sign, is lethargy/unconsciousness a danger sign, is convulsion a danger sign, is a baby who did not cry a danger sign, is fever a danger sign, is coldness a danger sign, is pus discharge from the umbilicus a danger sign, is poor feeding or unable to suckle a danger sign, is persistent vomiting a danger sign, and is diarrhoea a danger sign? The total knowledge score ranges between 0 and 10. Those who scored equal or more than the mean were classified as having good knowledge and those who scored below the mean were classified as having poor knowledge.

\section{Independent variable}

The independent variables were sociodemographic factors (age, age of the child, residence, income, educational status of wife and husband, occupation of husband and wife, marital status, age at marriage, religion, family size), history of infant illness, place of seeking care, decision-maker during care-seeking, number of children (birth order), index baby's place of birth and mode of delivery, wife's antenatal care (ANC) visit and frequency, husband accompanied the wife during maternal and child health (MCH) service visit, and source of information about neonatal danger signs.

\section{Operational definition}

- Neonatal danger signs: signs that indicate abnormal health conditions and that happen during the first 28 days of life. ${ }^{17}$

- Knowledge: husbands' level of awareness or mindfulness about neonatal danger signs. There were a total of 10 questions to assess and each correct response was given a score of ' 1 ', while an incorrect or unsure response was given a score of ' 0 '. The total knowledge score ranges between 0 and $10{ }^{18}$

- Good knowledge: husbands who score greater than or equal to the mean ( 5 or more) of the total knowledgebased questions. ${ }^{19}$

- Poor knowledge: husbands who have a score below the mean of the total knowledge-based questions. ${ }^{19}$

\section{Data collection procedure and technique}

After reviewing relevant literature from previous related studies and other materials, the questionnaire was prepared in English ${ }^{511} 18-21$ and translated to Amharic (the local language spoken in the area) by experts, and then back-translated to English to check for consistency. The questionnaire was administered with the Amharic version to facilitate understanding. The questionnaire used to assess knowledge was adopted from the WHO questionnaire, which is a standardised and structured questionnaire used internationally. ${ }^{15}$ The Amharic version of the questionnaire has been validated in mothers as a screening tool in Addis Ababa, Ethiopia, with a sensitivity and a specificity of 78.9 and 75.3, respectively. Two days of training were provided to the data collectors and supervisors, and the questionnaire was pretested a week before the actual survey in a comparable setting in the town of Agena on 5\% of the calculated sample size, after which the necessary corrections and modifications were made accordingly.

Data were collected by 20 experienced and trained data collectors, who are bachelor's degree holders, through a face-to-face interview using a structured questionnaire during household visits. Two experienced supervisors supervised the data collection process. Before the interview, the data collectors provided information about the aim of the study, the purpose, possible risks and benefits, participants' rights to refuse participation in the study, and confidentiality issues. Husbands who were willing to participate and signed the voluntary consent were then interviewed. Data collection was done for 28 consecutive days. The data collectors visit up to three times if they did not see the participant at the first home visit, and participants who were not available after three visits were included as non-respondents. Completed questionnaires were checked daily for completeness and internal consistency.

\section{Data processing and analysis}

The collected data were checked and reviewed for completeness, coded, cleaned, edited and entered into EpiData V.3.1, and exported to SPSS V.24 for analysis. Descriptive statistics were used to determine the frequency of different variables. The data were then presented using simple frequencies, tables and figures. The associations between the dependent and independent variables were examined using bivariable and multivariable logistic regression models. Variables $(\mathrm{p}<0.25)^{18}$ in the bivariate analysis were included in the final model of multivariate analysis controlling for all possible confounders. 
Multicollinearity was checked to see the linear correlation among the independent variables by using SE. Variables with an $\mathrm{SE}$ of $>2$ were dropped from the multivariable analysis. Model fitness was checked using the HosmerLemeshow test. The direction and strength of statistical association were measured by OR with $95 \%$ CI using multivariable logistic regression analysis. Adjusted OR (AOR) along with 95\% CI was estimated to identify the factors associated with knowledge status. In this study a $p$ value $<0.05$ was considered to indicate statistically significant results.

\section{RESULTS}

\section{Sociodemographic characteristics of respondents}

A total of 618 respondents were included in the study, with a response rate of $97.6 \%$. The mean age of the respondents was 36.05 ( $\mathrm{SD} \pm 6.236$ ), with minimum and maximum ages of 22 and 59 years, respectively. Majority $(93.7 \%)$ of the respondents were married and $29.8 \%$ were government employees. Nearly two-thirds (62\%) of the respondents were urban residents, while the rest were rural residents. About $45 \%$ of the respondents had completed primary school. More than half $(52.8 \%)$ of the respondents had a family monthly income of $<3000$ Ethiopian birrs and only $6 \%$ had a monthly income of more than 10000 Ethiopian birrs (table 1).

\section{Obstetrics-related characteristics of respondents' wives}

Nearly three-fourths $(73.6 \%)$ of the respondents' wives had parity of more than or equal to two, while the rest were primiparous. Majority $(75.4 \%)$ of the respondents' wives had given birth in health centres. Almost all (96.6\%) of the wives had a history of ANC follow-up, but nearly half $(57.9 \%)$ of the husbands did not accompany them during the visit (table 2).

\section{Source of information on neonatal danger signs and neonatal illness}

Health professionals were the source of information on neonatal danger signs for more than three-fourths $(77 \%)$ of the respondents. Almost all $(94.2 \%)$ of the respondents' wives continued breast feeding for sick neonates, and majority $(71.2 \%)$ mentioned lack of cleanliness as a cause of neonatal illness (figure 1).

\section{Knowledge of neonatal danger signs}

In this study, $40.7 \%$ (95\% CI 36.3 to 44.2 ) of the participants have good knowledge of neonatal danger signs. Three-fourths $(73.9 \%)$ of the respondents knew at least one of the neonatal danger signs. Among the respondents who knew neonatal danger signs, majority $(63 \%)$ mentioned that difficulty/fast breathing is the most common neonatal danger sign.

\section{Predictors of knowledge of neonatal danger signs}

In multivariable logistic regression, residence, wife's mode of delivery, accompanying the wife during ANC visit, having three or more children and health professionals as source of information were significantly associated with husbands' knowledge.

Respondents who reside in urban areas were two times (AOR=2.037, 95\% CI 1.372 to 2.986) more likely to be knowledgeable than respondents who reside in rural areas. Respondents with an educational level of secondary and above were 4.533 times $(\mathrm{AOR}=4.533,95 \%$ CI 3.336 to 11.564) more likely to be knowledgeable than respondents with no formal education. Respondents whose wives had a history of instrumental vaginal delivery were three times (AOR=3.01, $95 \%$ CI 2.261 to 4.327 ) more likely to be knowledgeable than those whose wives had spontaneous vaginal delivery. Those who accompany their wives during the $\mathrm{ANC}$ visit were two times $(\mathrm{AOR}=2.109$, 95\% CI 1.442 to 3.64 ) more likely to be knowledgeable than their counterparts. Those who had three or more children were 2.8 times more knowledgeable than those with two or fewer children (AOR=2.815, 95\% CI 2.180 to 3.906). Husbands who acquired information from healthcare providers were 1.8 times more knowledgeable than those who acquired information from other sources (AOR=1.781, 95\% CI 1.120 to 2.642) (table 3).

\section{DISCUSSION}

In this study, we found that majority of husbands have a low level of knowledge of neonatal danger signs. This finding suggests that healthcare providers should take into account the potential risk of a low knowledge status in countries like Ethiopia, where husbands are decisionmakers for healthcare-seeking. Besides, this is vital to healthcare planners. This knowledge can be used to build relevant programmes, channelling scarce resources for teaching what is needed as opposed to imparting messages that are already known.

The overall knowledge status of husbands was $40.7 \%$. This finding is in line with studies done in Arba Minch (40.9\%), and is higher than studies done in the Enugu state of Nigeria (30.3\%), northwest Ethiopia (18.2\%) and the town of Wolkite $(31.2 \%)$. However, the result was lower than the findings in India (62\%), Addis Ababa, Ethiopia $(84 \%)$, and in Chencha district of Ethiopia (50.3\%). The discrepancy might be attributed to methodological differences and study settings, participants' sociodemographic characteristics, and availability and accessibility of health services infrastructures. ${ }^{15-19} 22$ Health system-related factors might have also contributed to the discrepancy due to the extensive work of health extension workers and various healthcare institutions in raising awareness about different MCH issues. In current Ethiopian healthcare set-up, access to health institutions is better and health extension workers play a role by providing health education on MCH conditions at the household level.

The study identified the different factors associated with the outcome variable, such as urban residence, health professionals as source of information, the husband's wife having a history of instrumental birth, accompanying the wife during ANC visit and educational level. 
Table 1 Sociodemographic characteristics of husbands of mothers who gave birth in the last 6 months in Gurage Zone, Southern Ethiopia, $2020(\mathrm{~N}=618)$

\begin{tabular}{|c|c|c|c|c|}
\hline \multirow[b]{2}{*}{ Variables } & \multirow[b]{2}{*}{ Category } & \multicolumn{2}{|l|}{ Knowledge } & \multirow[b]{2}{*}{ Total (\%) } \\
\hline & & Knowledgeable (\%) & Not knowledgeable (\%) & \\
\hline \multirow[t]{6}{*}{ Age of the father in years } & $20-24$ & $1(0.4)$ & $6(1.6)$ & $7(1.1)$ \\
\hline & $25-29$ & $31(12.3)$ & $63(17.2)$ & $95(15.4)$ \\
\hline & $30-34$ & $45(17.9)$ & $78(21.3)$ & $123(20)$ \\
\hline & $35-39$ & $92(36.5)$ & $138(37.7)$ & $230(37.2)$ \\
\hline & $40-44$ & $54(21.4)$ & $43(11.7)$ & $97(15.7)$ \\
\hline & $>44$ & $29(11.5)$ & $37(10.1)$ & $66(10.7)$ \\
\hline \multirow[t]{2}{*}{ Age of the child in days } & $0-28$ & $37(14.7)$ & $52(14.2)$ & $89(14.4)$ \\
\hline & $>28$ & $215(85.3)$ & $314(85.8)$ & $529(85.6)$ \\
\hline \multirow[t]{4}{*}{ Marital status } & Married & $233(92.5)$ & $346(94.5)$ & $579(93.7)$ \\
\hline & Single & $12(4.8)$ & $8(2.2)$ & $20(3.2)$ \\
\hline & Divorced & $3(1.2)$ & $3(0.8)$ & $6(1)$ \\
\hline & Widowed & $4(1.6)$ & $9(2.5)$ & $13(2.1)$ \\
\hline \multirow[t]{5}{*}{ Religion } & Protestant & $27(10.7)$ & $48(13.1)$ & $75(12.1)$ \\
\hline & Orthodox & $114(45.2)$ & $193(52.7)$ & $307(49.7)$ \\
\hline & Catholic & $47(18.7)$ & $30(8.2)$ & 77 (12.5) \\
\hline & Muslim & $62(24.6)$ & $94(25.7)$ & $156(25.2)$ \\
\hline & Traditional & $2(0.8)$ & $1(0.3)$ & $3(0.5)$ \\
\hline \multirow[t]{3}{*}{ Father's level of education } & No formal education & $1(0.4)$ & $93(25.4)$ & $94(15.2)$ \\
\hline & Primary & $12(4.8)$ & $266(72.7)$ & $278(45)$ \\
\hline & Secondary and above & $239(94.8)$ & $7(1.9)$ & $246(39.8)$ \\
\hline \multirow[t]{5}{*}{ Father's occupation } & Government employee & $54(21.4)$ & $130(35.5)$ & $184(29.8)$ \\
\hline & Private employee & $37(14.7)$ & $67(18.3)$ & $104(16.8)$ \\
\hline & Student & $1(0.4)$ & $7(2)$ & $8(1.3)$ \\
\hline & Merchant & $63(25)$ & $114(31.1)$ & $177(28.6)$ \\
\hline & Farmer & $97(38.5)$ & $48(13.1)$ & $145(23.5$ \\
\hline \multirow[t]{3}{*}{ Mother's level of education } & No formal education & $1(0.4)$ & $109(29.8)$ & $110(17.8)$ \\
\hline & Primary & $16(6.3)$ & $251(68)$ & 267 (43.2) \\
\hline & Secondary and above & $235(93.3)$ & $6(1.6)$ & $241(39)$ \\
\hline \multirow[t]{6}{*}{ Mother's occupation } & Government employee & $33(13.1)$ & $82(22.4)$ & $115(18.6)$ \\
\hline & Private employee & $19(7.5)$ & $23(6.3)$ & $42(6.8)$ \\
\hline & Student & $2(0.8)$ & $9(2.5)$ & $11(1.8)$ \\
\hline & Merchant & 49 (19.4) & $138(37.7)$ & $187(30.2)$ \\
\hline & Farmer & $75(29.8)$ & $18(5)$ & $93(15)$ \\
\hline & Housewife & $74(29.4)$ & $96(26.2)$ & $170(27.5)$ \\
\hline \multirow[t]{3}{*}{ Family size } & $1-3$ & $33(13.1)$ & $75(20.5)$ & $108(17.5)$ \\
\hline & $4-6$ & $193(76.6)$ & $264(72.1)$ & $457(74)$ \\
\hline & $\geq 7$ & $26(10.3)$ & $27(7.4)$ & $53(8.6)$ \\
\hline
\end{tabular}

Respondents who reside in urban areas were 2.037 times more likely to be knowledgeable than their counterparts. This finding is similar to the study done in Gamo Gofa Zone. ${ }^{23}$ The reason may be that living in an urban area provides them better access to different information about health. Access to healthcare services is also better in urban areas. Meanwhile, rural residents may not acquire information that can help them with decision-making regarding healthy behaviours, including $\mathrm{MCH}$ education. Hence, rural residents lack access to infrastructures such as mass media which could enable them to acquire information related to health.

Husbands whose wives had a history of instrumental vaginal birth were 3.01 times more likely to be 
Table 2 Obstetric characteristics of mothers who gave birth in the last 6 months in Gurage Zone, Southern Ethiopia, 2020 $(\mathrm{N}=618)$

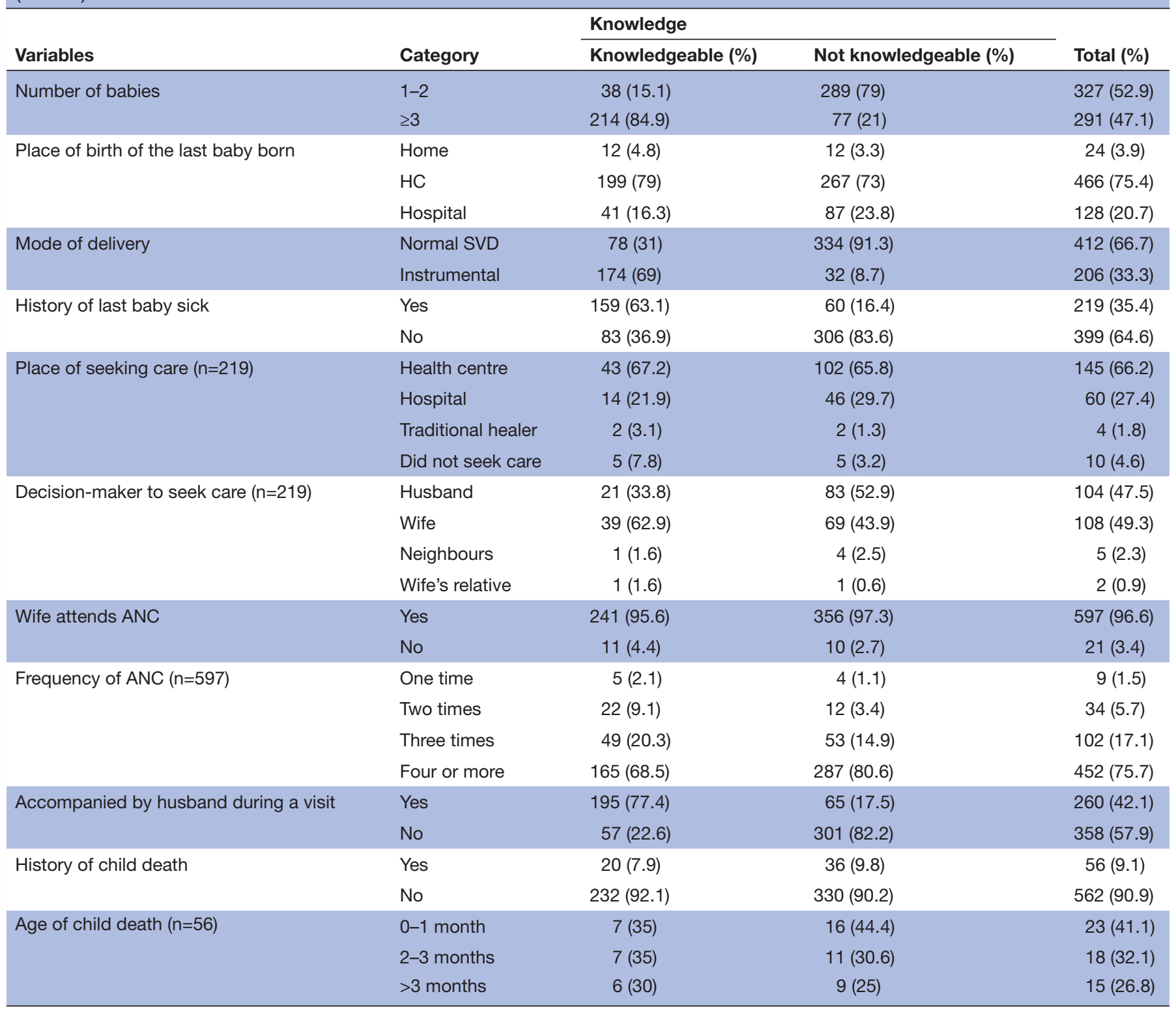

ANC, antenatal care; HC, health center; SVD, spontanous vaginal delivery.

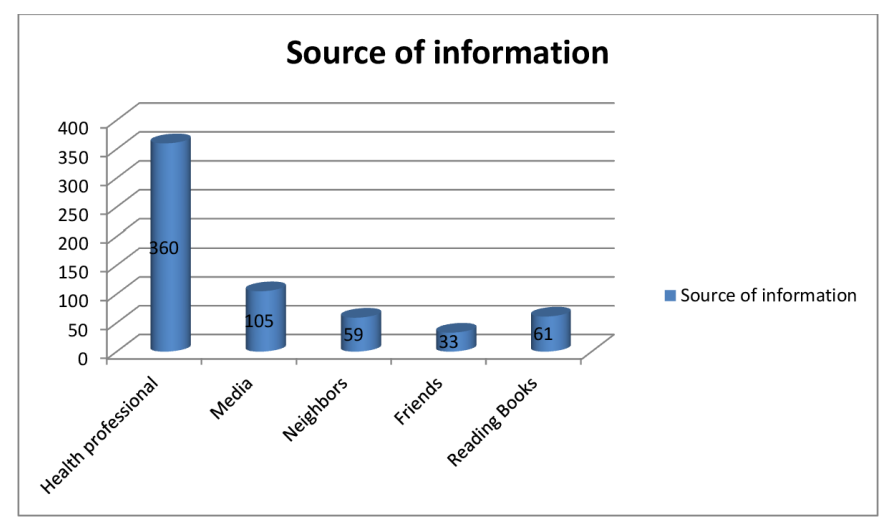

Figure 1 Source of information on neonatal danger signs among husbands of mothers who gave birth in the last 6 months in Gurage Zone, Southern Ethiopia, 2020. knowledgeable than those whose wives had spontaneous vaginal birth. This might be because when there is instrumental delivery there is an increased likelihood of staying at health institutions, which may increase husbands' contact with healthcare providers, thus increasing their opportunity to acquire knowledge about their babies' condition. This is in line with a study conducted in Northern Ethiopia. ${ }^{24}$

Husbands who accompany their wives during ANC visits were two times more likely to be knowledgeable than their counterparts. This may be because those who accompany their wives during ANC visits may receive counselling from health professionals, with emphasis on pregnancy and newborns, as well as the fact that most of the time husbands who accompany their wives are those who are more aware and more concerned about the health of the 
Table 3 Factors affecting knowledge of neonatal danger signs among husbands of mothers who gave birth in the last 6 months in Gurage Zone, Southern Ethiopia, 2020 (N=618)

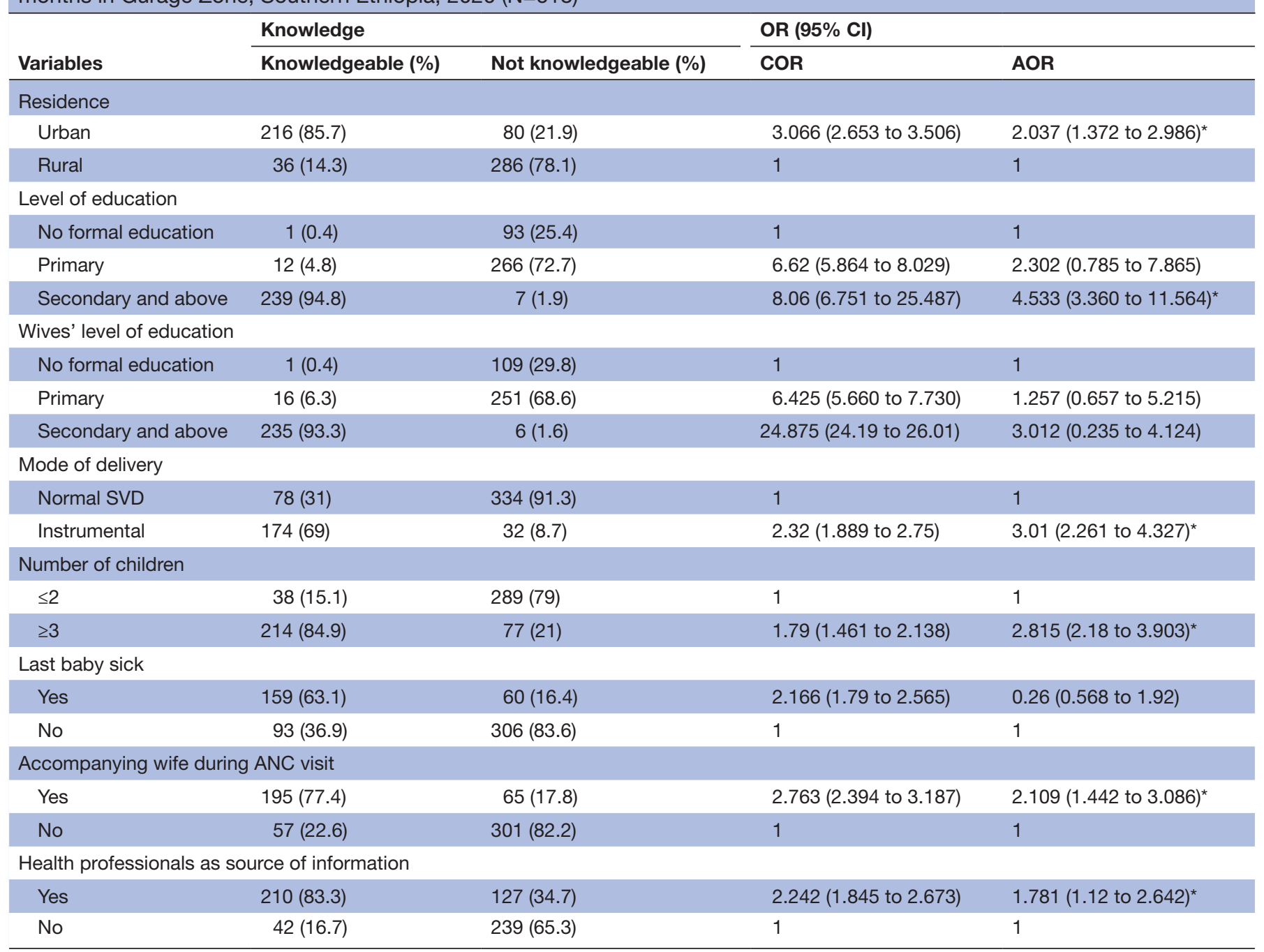

*Significant at $\mathrm{p} \leq 0.002$.

ANC, antenatal care; AOR, adjusted OR; COR, crude odd ratio; SVD, spontanous vaginal delivery.

family. This finding is similar to the study done in Gamo Gofa Zone. ${ }^{18}$

Husbands with three or more babies were 2.8 times more likely to be knowledgeable than those with two or fewer babies. This finding is in line with studies done in Kenyatta National Hospital and Tenta District in Ethiopia. ${ }^{25}$ The reason may be as the number of babies in the family increases, husbands' exposure to different problems increases, thus increasing their knowledge. Also, those who have more children will occasionally access health institutions, which may expose them to different information on danger signs.

Husbands who acquire information from health professionals were 1.78 times more likely to be knowledgeable than those who acquire information from other than health professionals. This finding is in line with the study done in Tenta District, Ethiopia. ${ }^{25}$ The reason may be due to health professionals being able to deliver appropriate information carefully, as well as the learners being able to pay more attention to the information that healthcare workers deliver.

Educational level was one predictor of knowledge status. Husbands with educational level of secondary and above were 4.53 times more likely to be knowledgeable than their counterparts. This finding agrees with studies conducted in Tenta District and in the town of Wolkite in Ethiopia. ${ }^{19}$ This may be due to the fact that when there is educational advancement knowledge of different conditions also increases. Also those who did not attend formal education may not easily understand the information given by care providers. ${ }^{26}$ Moreover, participants who had no formal education lack better awareness about the benefits of preventive healthcare and have lower receptivity to new health-related information.

\section{Strengths and limitations of the study}

The strengths of this research include it being the first study to be carried out in the study area, to the best of 
our knowledge. This was a community-based household survey which was important to explore factors that can predict the knowledge of husbands by addressing those who cannot visit health institutions due to different factors. Predictors of knowledge of danger signs would have been best addressed if the study included both the husband and the wife as study participants for comparison.

Due to the cross-sectional study design, the results might not indicate reverse causality.

\section{CONCLUSION}

Knowledge of neonatal danger signs among husbands in the study area was low. Urban residence, primary and above educational status, the wife delivering by instrument and the husband accompanying the wife during ANC visits were independent predictors of knowledge. This enforces health professionals and other stakeholders to pay attention to reducing the knowledge gap by improving husbands' attitude with regard to accompanying their wives during ANC visits since husbands are considered decision-makers when it comes to healthcareseeking in the family. Policymakers in the maternal health sector should also create a strategy to increase husbands' participation in accessing MCH service. The government should come up with policies that can help promote formal education for the community and increase their media access.

Acknowledgements We feel greatly indebted to the Wolkite University College of Medicine and Health Sciences Research and Community Service Directorate for giving this chance and building capacity. Our heartfelt thanks also go to Gurage Zone health office workers who gave support during data collection, the data collectors and all husbands in the study area who participated in this study.

Contributors SS and AM conceived of the study, carried out the overall design and execution of the study, performed the data collection and statistical analysis, and drafted the manuscript. HA, AY, AW and DA participated in the revision of the design of the study, data collection techniques and helped with the statistical analysis. All authors read and approved the final manuscript.

Funding The authors have not declared a specific grant for this research from any funding agency in the public, commercial or not-for-profit sectors.

Competing interests None declared.

Patient consent for publication Not required.

Ethics approval Ethical clearances were obtained from the research committee of the Wolkite University College of Medicine and Health Sciences (reference number WKU/RDD/2145/04/2020) given on 15 January 2020. Research ethics committees included Belayew Zeleke, Duba Adane and Natnael Esublew. A formal letter from Wolkite University was submitted to the concerned offices and Kebele extension workers. All study participants were informed about the purpose of the study and their right to refuse, and written and signed voluntary consent was obtained from them before the interview. The respondents were also informed that the information obtained will be kept confidential and will not cause them any harm. The study posed low or no more than minimal risk to the participants. The study also did not involve any invasive procedures. Moreover, confidentiality of information was guaranteed by using code numbers rather than personal identifiers and by keeping the data locked.

Provenance and peer review Not commissioned; externally peer reviewed.

Data availability statement Data are available upon reasonable request. All data relevant to the study are included in the article.

Open access This is an open access article distributed in accordance with the Creative Commons Attribution Non Commercial (CC BY-NC 4.0) license, which permits others to distribute, remix, adapt, build upon this work non-commercially, and license their derivative works on different terms, provided the original work is properly cited, appropriate credit is given, any changes made indicated, and the use is non-commercial. See: http://creativecommons.org/licenses/by-nc/4.0/.

\section{ORCID iDs}

Solomon Shitu http://orcid.org/0000-0002-9116-1162

Haimanot Abebe http://orcid.org/0000-0001-5885-5982

Daniel Adane http://orcid.org/0000-0002-3540-4844

Ayenew Mose http://orcid.org/0000-0003-4353-7791

Alex Yeshaneh http://orcid.org/0000-0001-5876-7325

\section{REFERENCES}

$1 \mathrm{WHO}$, Definition of the neonatal period. Southeast Asia regional Neonatal-Perinatal database

2 Nigatu SG, Worku AG, Dadi AF. Level of mother's knowledge about neonatal danger signs and associated factors in North West of Ethiopia: a community based study. BMC Res Notes 2015;8:309.

3 DuttaParul. Pediatric nursing. 1sted. New Delhi: Jaypee brother's medical publishers (p) Itd, 2011: 5, 66, 76, 85.

4 Choi Y, El Arifeen S, Mannan I, et al. Can mothers recognize neonata illness correctly? comparison of maternal report and assessment by community health workers in rural Bangladesh. Trop Med Int Health 2010;15:743-53.

5 Young Infants Clinical Signs Study Group. Clinical signs that predict severe illness in children under age 2 months: a multicentre study. Lancet 2008;371:135-42.

6 Piyush G. Essential pediatric nursing. 3rd edn. New Delhi: A.P.Jain and co-publication, 2010: 6. 40.

$7 \mathrm{H}$ MM. New-Born care practices by the mother/caregivers and their knowledge about signs of the sickness of neonates. Bangladesh $J$ Child Health 2011;35:90-6.

8 You D, Hug L, Ejdemyr S, et al. Global, regional, and national levels and trends in under-5 mortality between 1990 and 2015, with scenario-based projections to 2030: a systematic analysis by the un Inter-agency group for child mortality estimation. Lancet 2015;386:2275-86.

9 Mekonnen Y, Tensou B, Telake DS, et al. Neonatal mortality in Ethiopia: trends and determinants. BMC Public Health 2013;13:483.

10 Webair $\mathrm{HH}$, Bin-Gouth AS. Factors affecting health seeking behavior for common childhood illnesses in Yemen. Patient Prefer Adherence 2013;7:1129-38.

11 American International Journal of Research in Humanities, Arts and Social Sciences. Knowledge on warning signs of newborn illness among the mothers to develop an information booklet MS. ANU Dominic1, MS. ANU Joy1, MS. ANU P.S1, MS. Anumol Kurian1, MS. Arya Jose1, Ms.Shilpa G.S2, Mrs. Umarani. J 3. Available: http:// www.iasir.net

12 Central Statistical Authority and ICF International. Ethiopia demographic and health survey 2011. Addis Ababa, Ethiopia, and Calverton, Maryland, USA: Central Statistical Agency, 2012.

13 Hospital Care for Children. The global resource for addressing the quality of care. Danger signs in newborns and young infants, 2016. Available: http://www.ichrc.org/chapter-36danger-signs-newbornsand-young-infant

14 Haimanot A, Abebaw W, Alex Y. Determinant factors of neonatal near miss among neonates in Gurage zone hospitals. 12. Ethiopia: A Case-Control Study. Pediatric Health, Medicine and Therapeutics, 2021.

15 Sandberg J, Odberg Pettersson K, Asp G, et al. Inadequate knowledge of neonatal danger signs among recently delivered women in southwestern rural Uganda: a community survey. PLoS One 2014;9:e97253.

16 Gurage zone health administration report, 2018

17 Dereje B, Gizachew A, TekaGirma T. Involvement of male in antenatal care, birth preparedness and complication readiness and associated factors in Ambo town, Ethiopia. Journal of Health, Medicine, and Nursing 2016;27:2422-8419.

18 Kibaru EG, Otara AM. Knowledge of neonatal danger signs among mothers attending well baby clinic in Nakuru central district, Kenya: cross sectional descriptive study. BMC Res Notes 2016;9:481.

19 Abera M, Nega A, Kedir T, et al. Mother's Level of Knowledge on Neonatal Danger Signs and Its Predictors in Chencha District, Southern Ethiopia. American Journal of Nursing Science 2017;6:426-32.

20 Anmut W, Fekecha B, Demeke T. Mother's knowledge and Practice about Neonatal Danger Signs and Associated Factors in Wolkite Town, Gurage Zone, SNNPR, Ethiopia, 2017. J Biomedical Sci 2017;06:33. 
21 Bhandari N, Bahl R, Taneja S. Pathways to infant mortality in urban slums of Delhi, India: implications for improving the quality of community-and hospital-based programs. Journal of Health, Population and Nutrition 2002;20:148-55.

22 Dongre AR, Deshmukh PR, Garg BS. A community based approach to improve health care seeking for newborn danger signs in rural Wardha, India. Indian J Pediatr 2009;76:45-50.

23 Mrisho M, Schellenberg JA, Mushi AK, et al. Understanding homebased neonatal care practice in rural southern Tanzania. Trans $R$ Soc Trop Med Hyg 2008;102:669-78.
24 Fisseha Mulatu Assefa. Knowledge and health care seeking behavior of mothers about neonatal danger sign, 2014. Available: etd.aau.edu. et

25 Shaikh BT, Hatcher J. Health seeking behaviour and health service utilization in Pakistan: challenging the policy makers. J Public Health 2005;27:49-54

$26 \mathrm{WHO}$, postnatal care for mothers and newborns highlights from the World Health Organization 2013 Guidelines, WHO Library Cataloguing-in-Publication data world, 2015. Available: http://www. mcsprogram.org 